\title{
An Experiment on Idem Identity in the Qumran Movement
}

\author{
Jokiranta, Jutta
}

2009

Jokiranta , J 2009 , ' An Experiment on Idem Identity in the Qumran Movement ' , Dead Sea

Discoveries , vol. 16 , no. 3 , pp. 309-329 . https://doi.org/10.1163/156851709X473941

http://hdl.handle.net/10138/217506

https://doi.org/10.1163/156851709X473941

publishedVersion

Downloaded from Helda, University of Helsinki institutional repository.

This is an electronic reprint of the original article.

This reprint may differ from the original in pagination and typographic detail.

Please cite the original version. 


\title{
An Experiment on Idem Identity in the Qumran Movement
}

\author{
Jutta Jokiranta \\ Helsinki Collegium for Advanced Studies, University of Helsinki \\ P.O. Box 4, FIN-00014 University of Helsinki, Finland \\ jutta.jokiranta@helsinki.fi
}

\begin{abstract}
The debate on the relationship between the Rule of the Community (S) and the Damascus Document (D) can be distorted by concentrating on the differences between the documents, without a clear appreciation of the significance of their mutual correspondences. The concept of idem identity is here adopted to demonstrate that what the movement was considered to be is at least as important to ask as who its members were considered (and considered themselves) to be (questions of their ipse identity). The movement could be perceived to be the same, persisting overtime, despite various kinds of differences. The article seeks to identify critical elements of diversity allowed within the same movement. An experiment on the idem identity is provided by looking at the rule documents and the admission in particular. In its shared social identity, the movement seems to depict itself rather in terms of its activities such as counsel and qualifications than particular forms of communities and organizations.
\end{abstract}

\section{Keywords}

Social identity, sameness, Rule of the Community, Damascus Document, Qumran movement, admission

Identity is an elusive concept. This paper offers conceptual tools for talking about identity and defining which aspects of identity are relevant in different investigations, using both philosophical concepts and insights from the social identity approach. More specifically, the paper will discuss the idem identity of the Qumran movement: ${ }^{1}$ the question of how the

1 The "Qumran movement" is, in my view, a practical term to designate the 
members in this particular sectarian movement might have perceived the conditions for sameness over time.

\section{Concepts, Theoretical Frameworks and the Task}

According to one conceptual analysis of "identity," a distinction can be made between idem identity (identity as sameness), and ipse identity (identity as selfhood). ${ }^{2}$ Idem identity refers to those conditions which determine that an entity is the same at time $t 1$ as at time $t 2 .{ }^{3}$ This sameness can be investigated concerning any entity, not just human beings. Usually, some change is allowed over time and yet sameness is preserved. We do not question the sameness of a pencil or a sunset now and five minutes ago, even though there could be differences in them now and then. It is a matter of what an entity is understood to be. If a human being is understood to be a biological creature, for example, s/he is the same human being even though s/he changes, grows up, or loses mental ability, e.g., consciousness.

This meaning of identity is useful when scholars investigate the changes that took place in the Qumran movement. The question of whether we can speak of the same movement is raised in comparisons of the Damascus Document (D) and the Rule of the Community (S) communities especially: how much variation is allowed in order to be able to speak of the same movement? What this movement is understood to be defines the answer. The question of whether the Qumran movement can be considered the

social movement whose members stood in tension with societal change and (at least some of them) were responsible for copying, preserving and composing the Dead Sea Scrolls, irrespective of where these members lived. The "Qumran community" refers to people at Qumran. Designations based on emic terminology are problematic, since those terms can be shared by only part of the members. The "Essenes" has a controversial tone. We need an etic title. "Qumran" could perhaps be replaced by "Dead Sea Scrolls" but this could be misunderstood to refer to a literary level.

2 Paul Ricoeur, Oneself as Another (Chicago: The University of Chicago Press, 1992). I wish to thank Arto Laitinen, Research Fellow at the Helsinki Collegium for Advanced Studies, for bringing this distinction to my attention.

${ }^{3}$ For this philosophical question, see Richard Sorabji, Self: Ancient and Modern Insights about Individuality, Life, and Death (Chicago: The University of Chicago Press, 2006), 94-111. 
same as the Essenes of the Classical Sources also has to do with sameness. In this case, two entities exist: we know they are not one entity, but we may ask to what extent they are identical. ${ }^{4}$ Thus, speaking about the "identity of the Qumran community/ies" can mean scholarly identifications of these groupings with one or none of the other Second Temple Jewish groups (etic point of view). Whether or not we perceive the communities as being the same is, of course, relevant for many research questions, including the right to use one set of sources to illuminate another set of sources. However, the object of the inquiry is historical, and the Dead Sea Scrolls provide us partial historical evidence from the ancient people themselves (emic point of view).

Ipse identity, on the other hand, is one's selfhood, created by interpretative processes in which an individual reflects on the question "Who am I?" and lives accordingly. ${ }^{5}$ This identity is not constituted by facts about the self or by others' perceptions of the self, but by the individual's experiences and interpretations of self. The self exists in these interpretations; it is not something separate from them. ${ }^{6}$ To illustrate the distinction between idem identity and ipse identity, we may think of a person who, tragically, tells his/her partner, "I am not the person you fell in love with." This claim is false in the sense of the idem identity (it is the same person-hence the

${ }^{4}$ This is qualitative sameness/identity: two television sets can be identical but they are not one entity. See Arto Laitinen, Strong Evaluation Without Sources: On Charles Taylor's Philosophical Anthropology and Cultural Moral Realism (Jyväskylä Studies in Education, Psychology and Social Research 224; Jyväskylä: University of Jyväskylä, 2003), 116.

5 Ipse identity is something that belongs to self-reflective animals only, see Charles Taylor, Human Agency and Language: Philosophical Papers I (Cambridge: Cambridge University Press, 1985), 45. Studies in philosophy have often centered on the question of what has changed in the perception of the self from antiquity and the middle ages to modern times. Humans, including infants, have the need tosee the world in relation to themselves. Persons might not have a strong sense of self but they still view the world in terms of self (or, in some cases, in terms of many selves), see Sorabji, Self, 23. For the discussion of the anachronistic but continued relevance of the concept "identity" in antiquity, see Judith M. Lieu, Christian Identity in the Jewish and Graeco-Roman World (Oxford: Oxford University Press, 2004).

${ }^{6}$ However, a person/subject/human being can be seen to exist independently of the self, see Laitinen, Strong Evaluation Without Sources, 8. According to Sorabji, (Self, 21), a person has or owns psychological states and actions. 
tragedy), and true in the sense of the ipse identity (what kind of person one sees oneself to be). ${ }^{7}$ Idem identity is about what constitutes the same person(s)/things at different times, and ipse identity is about what differentiates people at the same time. ${ }^{8}$

I have previously used the concept "social identity" and insights from the social identity approach — a social psychological approach—in discussion about identity. ${ }^{9}$ How do ipse and idem identities relate to this approach and why are all of these concepts necessary in order to speak of the ancient phenomena?

The social identity approach reminds us about the social-psychological processes and fluidity relevant to understanding the ipse and idem identities. The approach claims that the essential parts of the ipse identity (although that concept is not used in the approach) are constructed in a social process. A theoretical distinction is made between one's personal identity and one's social identity. Personal identity is one's perception of oneself as a distinct individual. "Social identity" is a conceptual tool,

7 This example is from a discussion with Arto Laitinen.

8 Sorabji, Self, 2.

9 Jutta Jokiranta, "Identity on a Continuum: Constructing and Expressing Sectarian Social Identity in Qumran Serakhim and Pesharim" (Ph.D. diss., Helsinki University, 2005), which includes the articles: "The Prototypical Teacher in the Qumran Pesharim: A Social Identity Approach," in Ancient Israel: The Old Testament in Its Social Context (ed. Philip F. Esler; Minneapolis: Fortress Press, 2006), 254-63; "Social Identity Approach: Identity-Constructing Elements in the Psalms Pesher," in Defining Identities: We, You, and the Other in the Dead Sea Scrolls: Proceedings of the Fifth Meeting of the IOQS in Groningen (ed. Florentino García Martínez and Mladen Popović; STDJ 70; Leiden: Brill, 2008), 85-109. Literature on the social identity approach is vast. For the introduction to the approach, see Dominic Abrams and Michael A. Hogg, eds., Social Identity Theory: Constructive and Critical Advances (New York: Harvester Wheatsheaf, 1990); W. Peter Robinson, ed., Social Groups and Identities: Developing the Legacy of Henri Tajfel (International Series in Social Psychology; Oxford: ButterworthHeinemann, 1996).

${ }^{10}$ According to one philosophical conceptualization, "individual identity" includes, for example, biographical identity (one's narrative of life events and experiences that are considered important for forming the self); practical identity (one's commitment to certain values and goals in life); qualitative identity (personal characteristics that one feels important in a given situation); numerical identity (one's sense of one's singularity). See Laitinen, Strong Evaluation Without Sources, 118. My claim is that social identities can play a part in one's ipse identity 
limited to describing "that part of an individual's self concept which derives from his knowledge of his membership of a social group together with the value and emotional significance attached to that membership."11 A person's self-conception reflects self-categorization, "the cognitive grouping of the self as identical to some class of stimuli in contrast to some other class of stimuli." 12 This includes accentuation of in-group similarities and exaggeration of differences from out-groups. The comparative nature of social identity makes it relative in terms of various situations; variant social identities can be salient at different times and places, and social identities form hierarchies. ${ }^{13}$ Social categories are never fixed but dynamic and flexible.

in various ways: as part of the biographical identity (group memberships constitute important stages in the individual's life), as part of the practical identity (a significant goal is tied to a group membership), and as part of the qualitative identity (the individual categorizes him/herself in terms of group characteristic in a given situation), even as part of one's numerical identity (the individual sees $\mathrm{him} /$ herself as the same person since s/he continues to belong to the same social entities). However, Laitinen (Strong Evaluation Without Sources, 128) relates most social identities only to qualitative identity. Combining these theoretical perspectives, I would say that, in the sense that social identity is an individual's perception of him/herself, social identity is a narrower concept than the ipse identity; the ipse identity can take the form of a social identity.

${ }^{11}$ Henri Tajfel, Differentiation between Social Groups: Studies in the Social Psychology of Intergroup Relations (London: Academic Press, 1978), 63. It thus includes three dimensions: identification, value judgment and emotional attachment. Group memberships can in theory be anything; they are based on features regulated by the group itself. Some given features (e.g., skin color) often constitute group memberships and some given features not (e.g., length of hairalthough this can also constitute a group).

12 John C. Turner, "Some Current Issues in Research on Social Identity and Self-Categorization Theories," in Social Identity: Context, Commitment, Content (ed. Naomi Ellemers, Russel Spears, and Bertjan Doosje; Oxford: Blackwell, 1999), 6-34 (12).

${ }_{13}$ Michael A. Hogg and Dominic Abrams, Social Identifications: A Social Psychology of Intergroup Relations and Group Processes (London: Routledge, 1988); Michael A. Hogg and Craig McGarty, "Self-Categorization and Social Identity," in Abrams and Hogg, eds., Social Identity Theory: Constructive and Critical Advances, 10-27; S. Alexander Haslam, Psychology in Organizations: The Social Identity Approach (2nd ed.; London: SAGE, 2004). The salience of a category depends on its relevance to the situation: a comparative fit determines the level at 
It makes a great difference whether we think of identity as something given or something constructed. ${ }^{14}$ The distinction between idem identity and ipse identity can serve here as well: idem identity is something that precedes our interpretations and is thus, in a way, given. ${ }^{15}$ We perceive ourselves to be the same today as yesterday, and twenty years earlier, even though many things have changed in the kind of persons we perceive ourselves to be. Ipse identity, on the other hand, is created through interpretations in various situations and it is thus constituted. To claim that ipse identity is "constructed" can imply a conscious, reflective, and active process, which is not always the case. Many parts of identity can be unconscious, and individuals are not "free" to choose whatever aspects they wish to include in their identity. Social identities can be seen as given in the sense that people in any society internalize social categorizations that are around them. ${ }^{16}$ Yet, they are always situational and dynamic, sort of "social contextual definitions of the individual." ${ }^{17}$

The Dead Sea Scrolls are full of metaphors that can be taken as identity markers. But not all such metaphorical identities were operative at the same time. Some were evidently more primary than others, some were on a higher level of abstraction than others, and some probably varied from group to group or from time to time. Social identity is more than categorization: it includes identification, the emotional and valuative significance of that group membership for the person. Not all group members have the same degree of identification and apply the same meaning to this identifi-

which differences from other in-group members are perceived to be smaller than differences from relevant out-group members. Furthermore, a normative fit refers to a person's previous experiences and knowledge, which affect the categorization process in determining what differences are perceived to be relevant. The accentuation effect, the perception of in-group members as homogeneous and respectively different from out-group members, is more pronounced when the category is important and of immediate relevance to the individual.

${ }_{14}$ The distinction is noted by Carol A. Newsom, The Self as Symbolic Space: Constructing Identity and Community at Qumran (STDJ 52; Leiden: Brill, 2004), 192.

15 Cf. Laitinen, Strong Evaluation Without Sources, 130.

${ }^{16}$ John C. Turner, "Henri Tajfel: An Introduction," in Robinson, ed., Social Groups and Identities, 1-23 (17).

${ }^{17}$ John C. Turner and Richard Y. Bourhis, "Social Identity, Interdependence and the Social Group: A Reply to Rabbie et al.," in Robinson, ed., Social Groups and Identities, 25-63 (32). 
cation: to be European does not mean the same to every person who categorizes him/herself as a European. ${ }^{18}$ What, then, is the justification for speaking of a shared social identity? Is this an average of all the individual social identities or something else? Do groups have a collective identity?

Social identity theorists maintain that "the social nature of identities implies that there is a socially based construction of meaning as well, leading people to show consensus in at least some aspects of the identity definition." ${ }^{19}$ Social identity involves an ongoing and dynamic process by which the individuals "show consensus" and adopt shared meanings. Naturally, contentious and deviating stances may also occur. Therefore, any metaphorical representation of the social identity in the Scrolls, such as the "new covenant in the land of Damascus" (CD 19: 33-34), "yahad," "the most holy dwelling" (1QS 8:8), "covenant" (1QS 1:16; CD 2:2); "volunteers" (1QS 1:11); “congregation of Israel" (1QSa 1:1); "children of light" (1QM 1:1); "congregation of the poor" (4QpPs 2:10) are not to be treated as frozen and fixed, isolated from their textual worlds and directly transferred to the social world of the movement. It is probable that these labels and categories formed a network in the members' identities where some were more central than others, some perhaps not operative at all, and that categories formed hierarchical levels. For example, "Israel" is a high level category, but can, on the other hand, function as a lower level (restricted) category. ${ }^{20}$ "Israel" in D is not always at the same level of abstraction as is "yahad" in S. If a member identified him/herself as a member of the "yahad," it is possible that in comparison to nonJews, s/he still categorized him/herself as an "Israelite." Or consider the "camp" language in D. Whether or not it was at all an identity category (“camp-member"), or a theological statement on biblical wilderness ideas

18 Kay Deaux ("Models, Meanings and Motivations," in Social Identity Processes: Trends in Theory and Research [ed. Dora Capozza and Rupert Brown; London: SAGE, 2000], 1-14 (6)) refers to a study in which great variation was found concerning the contents of Hispanic identity among Hispanic students. Attempts have been made to analyze the dimensions of difference within a social identity category, e.g., cognitive, evaluative and behavioral dimensions of social identification.

19 Deaux, "Models, Meanings and Motivations," 6.

20 Cf. John J. Collins, "The Construction of Israel in the Sectarian Rule Books," in Judaism in Late Antiquity, Part 5: The Judaisms of Qumran: A Systemic reading of the Dead Sea Scrolls, Vol. 1: Theory of Israel (ed. Alan J. Avery-Peck, Jacob Neusner, and Bruce Chilton; Leiden: Brill, 2001), 25-42. 
("wilderness-member-exiled but blessed") ${ }^{21}$ is an important question to ask.22

Now the research question can be formulated more clearly: to what extent is it likely that the available social identities of the members of the Qumran movement at one time were the same as at another time? In other words, if they perceived "us" in one way at time $t 1$, which differences were allowed in the definition of "us" at time $\mathrm{t} 2$ for the movement to be the same? The question thus investigates the sameness of the ipse identity (in this case, its social aspect) and the answer partly defines the grounds on which we can speak of the idem identity of the Qumran movement, its sameness over time.

\section{Experimenting on Rule Documents}

This article limits the inquiry to $\mathrm{D}$ and $\mathrm{S}$. The relationship between $\mathrm{D}$ and $S$ and other rulebooks (e.g., 1QSa; 4Q265) as well as the development within these manuscript traditions have been a continuous interest among scholars. ${ }^{23}$ Recently, Hilary Kapfer presented a survey of some of the views in favor of the chronological primacy of either $\mathrm{D}$ or $\mathrm{S}$; she herself defends the primacy of $\mathrm{D}$ on the basis of the attitudes towards the Temple. ${ }^{24}$ The community of $\mathrm{D}$ is commonly seen either as a parent movement of the $S$

${ }^{21}$ See Liv Lied, "Another Look at the Land of Damascus: The Spaces of the Damascus Document in the Light of Edward W. Soja's Thirdspace Approach," in New Directions in Qumran Studies: Proceedings of the Bristol Colloquium on the Dead Sea Scrolls, 8-10 September (ed. Jonathan G. Campbell, William John Lyons, and Lloyd K. Pietersen; London: T\&T Clark, 2005), 101-25.

${ }^{22}$ If the former, it stands in distinction to "city-members:" sex was prohibited in the holy city (CD 12:1-2; also 12:19-20), but family life was carried out in the camps (CD 7:6b-9a // 19:1-5a). The Cave 4 fragments of D mention together "all who dwell in their [c] amps and all who d[well in] their [cities]" (4QD 7 ii 14; reconstructed also in 4QD $1120 / / 4 \mathrm{QD}^{\mathrm{d}} 16$ 18).

${ }^{23}$ For literature, see Charlotte Hempel, The Damascus Texts (Companion to the Qumran Scrolls 1; Sheffield: Sheffield Academic Press, 2000), and Sarianna Metso, The Serekh Texts (Companion to the Qumran Scrolls 9; London: T\&T Clark, 2007).

${ }^{24}$ Hilary Evans Kapfer, "The Relationship between the Damascus Document and the Community Rule: Attitudes towards the Temple as a Test Case," DSD 14 (2007): 152-77. 
community, or a larger movement of which the $S$ community is a part. However, the idea that $\mathrm{D}$ is later than $\mathrm{S}$ has also found support, as Kapfer shows, and most recently, Eyal Regev postulates the "D sect" as a later and more hierarchical development of $S$, yet independent of it. ${ }^{25}$ The question of the relationship between these documents is also dependent on how scholars reconstruct the textual histories within $\mathrm{S}$ and $\mathrm{D}$ traditions. No consensus exists here either: the chronological order of individual manuscripts within one tradition, the $S$ tradition in particular, has not been established. ${ }^{26}$ In contrast to those scholars who regard the shorter $4 \mathrm{Q} \mathrm{S}^{\mathrm{b}, \mathrm{d}}$ manuscripts as early representatives of the $S$ tradition despite the late age of these copies, ${ }^{27}$ others see them as shortened versions of the longer and more original $S$ tradition such as $1 \mathrm{QS} .{ }^{28}$ These questions have direct relevance to the understanding of the movement, its make-up, authority structures and ideology, and sociological assumptions play a role in the conclusions one makes.

25 Kapfer, "The Relationship," 157-61; Eyal Regev, Sectarianism in Qumran: A Cross-Cultural Perspective (Religion and Society 45; Berlin: de Gruyter, 2007).

${ }_{26}$ The $\mathrm{D}$ tradition has much less variation than the $S$ tradition. Most extensively, the variations between the CD A and CD B manuscripts and their relationship have been debated; see, Hempel, Damascus Texts, 77-79.

27 E.g., Sarianna Metso, The Textual Development of the Qumran Community Rule (STDJ 21; Leiden: Brill, 1997); Charlotte Hempel, "The Literary Development of the S Tradition—a New Paradigm," RevQ22/87 (2007): 389-401 (391). According to this view, the shorter versions testify to early stages in the redactional process that lack complete sections of 1QS (e.g., columns 1-4 of 1QS), biblical quotations (e.g., Isa 40:3 of 1QS 8:14), more elaborate phrases (e.g., on the "people of injustice" in 1QS 5:11-13), and references to the "sons of Zadok" (e.g., in comparison to $1 \mathrm{QS} 5: 2$ ), etc.

28 E.g., P. S. Alexander, "The Redaction-History of Serekh ha-Yahad: A Proposal," RevQ 17/65-68 (1996): 437-56. Recently, Devorah Dimant (“The Composite Character of the Qumran Sectarian Literature as an Indication of Its Date and Provenance," RevQ 22/88 [2006]: 615-30) argues that $1 Q S$ is a primary, early and even an official exemplar of the $S$ tradition on the basis of its early manuscript dating, its physical features as a carefully produced, large scroll, and the fact that it has been corrected which shows that it had an important status. Dimant thinks that the shorter recensions were abbreviated from a longer version, "perhaps copied for private use" (619). 
I am interested in seeking to explore alternative-or complementarymethodological ways of proceeding, in comparison with those who have investigated the "Judaisms" of D and $S,{ }^{29}$ and with those who quickly translate the perceived differences between D and S into "communities," often a "parent" and a "child" one, but also with those who read the documents synchronically at a literary level. I shall speak heuristically of "D members" and "S members" as hypothetical constructs of the implied users of the respective documents and the kinds of persons they constructed, although the functions of the documents are not clear-they may not have constituted a community in the first place-and, in reality, there could have existed an "X-type of membership" with features from both or neither of them (and, in theory, a myriad of memberships). This is a heuristic enterprise. The thought-experiment is intentionally biased towards finding a basis for perceptions of togetherness, sameness and continuity, in spite of differences, distinctions and discontinuity. Members that share the same identity could easily find elements that differentiate between them; sameness is created in distinction to something on the outside and needs constant maintenance.

\section{Idem Identity within the S Tradition}

To discuss anything about the identities of the members, we have to start with the manuscript evidence. Whatever direction one takes concerning the development of the $S$ tradition, it is to be noted that the shorter versions of $S$ are not simply building blocks of or extracts from the longer versions. Recently, Charlotte Hempel stressed that, concerning the terminology of the community (especially rabbim and the "council of the community"), some of the shorter traditions $\left(4 \mathrm{QS}^{\mathrm{d}}\right)$ testify to diversity within themselves. This suggests that some independent traditions were already brought together in these shorter versions or their predecessors. ${ }^{30}$ Hempel

${ }^{29}$ Philip R. Davies, "The Judaism(s) of the Damascus Document," in The Damascus Document: A Centennial of Discovery: Proceedings of the Third International Symposium of the Orion Center for the Study of the Dead Sea Scrolls and Associated Literature, 4-8 February, 1998 (ed. Joseph M. Baumgarten, Esther G. Chazon, and Avital Pinnick; STDJ 34; Leiden: Brill, 2000), 27-43.

${ }^{30}$ Hempel, "The Literary Development," 389-401. According to her, "[t]he developments are not confined to the boundaries of any of the preserved manu- 
sees continuity between various manuscripts in the traditions about "people of injustice," "sons of Aaron" and the "council of the community." It is more likely that these traditions stem from an early, common stratum rather than indicate a later redaction in various manuscripts. ${ }^{31}$ Devorah Dimant, who considers the manuscript datings to be sufficient evidence for the primacy of $1 \mathrm{QS}$ over against $4 \mathrm{QS}^{\mathrm{b}, \mathrm{d}}$ and takes the shorter versions as abbreviations of the longer, does not explain, however, why such abbreviations differed from the wordings of $1 \mathrm{QS}$, why they preserved the variety rather than harmonized it, and why they might have dropped out certain data. ${ }^{32}$ If the hypothesis of the primacy of $1 \mathrm{QS}$ is to be supported, these aspects call for further explanations. Dimant admits that $1 \mathrm{QS}$ is a compilation and relies on earlier sources. ${ }^{33}$ If there were sources behind $1 \mathrm{QS}$, these would, in my mind, be something very similar to what we find in 4QS manuscripts that preserve shorter sections - and thus, in any case, a setting where such shorter traditions were first created would have to be postulated. Dimant would place such a setting in a very early period, before the emergence of the "Qumran community," ${ }^{4}$ and Hempel speaks of

scripts" (393). The independence of the rabbîm and "council" language is suggested by the fact that some sections contain only one type of language but not the other, as Hempel states: "The presence of such passages that attest exclusively one set of terms indicates that the conflation is probably secondary" (398). These perspectives could also be used to oppose the view by John J. Collins ("Forms of Community in the Dead Sea Scrolls," in Emanuel: Studies in Hebrew Bible, Septuagint, and Dead Sea Scrolls in Honor of Emanuel Tov [ed. Shalom M. Paul et al.; VTSup 94; Leiden: Brill, 2003], 97-111) of the "elite group" within yahad: section 1QS 8-9 does use again slightly different language (perfection and holiness) but this does not have to indicate the existence of an elite group but rather the elevation of a certain type of social identity, based on conflation of traditions.

31 Hempel, "The Literary Development," 395-96.

32 Dimant, "The Composite Character," 619-20. The personal use of a scroll would not exclude the possibility that it would preserve earlier, shorter traditions. It could well be conceivable that if the need to have handy portable versions arose, they could also use the earlier shorter traditions for this purpose.

33 Dimant, "The Composite Character," 621, stresses that "the existence of distinct sections, or even underlying sources, is not necessarily at odds with a single overall framework [of 1QS]."

34 Dimant, "The Composite Character," 622, writes that the sources "must date to the second half of the second century B.C.E. at the latest. Yet even at this early point these sources are already elaborate and use an evolved terminology." 
"primitive small scale contexts" for some early traditions. ${ }^{35}$ Even though these views on the development of the $S$ tradition contain some irreconcilable differences, both Dimant and Hempel seem to wish to see continuities more clearly (Dimant within 1QS as well as over later 4QS manuscripts; Hempel on the shared material in all manuscripts), and both see a long development before any of the existing manuscripts were created. The words of Hempel are indicative for our purpose: "It seems likely, therefore, that the terms rabbim and 'council of the community' emerged in distinct literary-and probably also communal - settings and were eventually conflated in parts of the $S$ tradition." ${ }^{36}$ If this is the case, such distinct settings testify to complexity within the movement. It seems to me that the very existence of separate traditions, some of which were brought together at various stages, testifies to the members' perception, according to which the movement was a heterogeneous, complex environment, of a great deal of freedom and variety. ${ }^{37}$

\section{Idem Identity between $\mathrm{D}$ and $\mathrm{S}$ traditions}

Concerning the relationship between the $S$ and $\mathrm{D}$ traditions, it is in some way or other assumed that communities lie behind the $S$ and $\mathrm{D}$ traditions. ${ }^{38}$ There seems to be fundamentally something different between $\mathrm{D}$ and $\mathrm{S}$, but every attempt to conceptualize this difference can be opposed with several "buts." The difficulty arises from the fact the lines between various

35 Hempel, "The Literary Development," 396.

36 Hempel, "The Literary Development," 400. My emphasis.

37 Unless, of course, it can be shown that the earlier traditions were preserved only for the sake of replacement by a later tradition. Further work is necessary to see which ideas actually override each other.

38 There are also other voices, cautious of finding groups behind texts, e.g., Philip R. Davies, "Sects from Texts: On the Problems of Doing a Sociology of the Qumran Literature," in New Directions in Qumran Studies, 69-82. Charlotte Hempel, The Laws of the Damascus Document: Sources, Tradition and Redaction (STDJ 29; Leiden: Brill, 1998), 36-37, rightly calls for caution in taking these rules as a direct window into the community life because of the strong scriptural orientation in many of them. In a similar way, Sarianna Metso, "Methodological Problems in Reconstructing History from Rule Texts Found at Qumran," DSD 11 (2004): 315-35 (332-33), points out that the Community Rule is not a prescriptive law book in the community. 
phases of the movement or between different groups cannot be drawn strictly between individual documents. A substantial amount of shared elements between the $\mathrm{D}$ and $\mathrm{S}$ traditions exists, and although not always identical, these elements testify to common literary traditions deemed significant by these groups: both describe a simple admission procedure with an oath (CD 15:5b-10a; $;^{39} 1 \mathrm{QS} 5: 7 \mathrm{c}-11 \mathrm{a} / / 4 \mathrm{QS}^{\mathrm{b}}$ 9:6b-8b; ${ }^{40} 4 \mathrm{QS}^{\mathrm{d}}$ 1:5b-7a); both demand separation from outsiders (e.g., CD 6:14b-15a; 1QS 9:16 ii; 4QSd 8:1b; 4QSe 3:13b-14a); both refer to confession of sins (CD 20:27b-30a; 1QS 1:24-2:1); both claim to have true knowledge of the divine law (CD 3:12b-16a; 1QS 4:6; 5:9, 11); both mention groups of ten (CD 13:1b-2; 1QS 6:6b-8a // 4QS $\left.{ }^{\mathrm{d}} 2: 7 \mathrm{~b}-8 \mathrm{a}\right)$; both structure their meetings hierarchically (CD 14:3-6; 1QS 6:8b-10a); both acknowledge the system of thousands, hundreds, fifties and tens (CD 13:1-2; 1QS 2:21-22); both refer to an annual renewal of the covenant and the cursing of the enemy (4QD ${ }^{a} 11$ 17-18a // 4QD 7 ii 11-12a; 1QS 2:4b-25a); both have an elaborate penal code (CD 14:20-22 // 4QD 10 i 14-ii 15// $4 \mathrm{QD}^{\mathrm{b}} 9$ vi // 4QD 11 i 4-ii 5; 16 // 4QD 7 i 1-21; 1QS 6:24-7:25 // $4 \mathrm{QS}^{\mathrm{d}} 5$ [frg. 2]; 4QS $\left.{ }^{\mathrm{e}} 1: 1-2: 9 ; 4 \mathrm{QS}^{\mathrm{s}} 3-6\right)$; both have instructions for the maśkîl (CD 12:20b-21a // 4QDa 9 ii 7; 1QS 3:13; 9:12; 1QS 9:21// $4 \mathrm{QS}^{\mathrm{b}}$ 18:5 // 4QS $8: 5 / / 4 \mathrm{QS}^{\mathrm{e}} 4: 2$; $4 \mathrm{QS}^{\mathrm{b}}$ 9:1 // 4QS ${ }^{\mathrm{d}} 1: 1$ ); both mention "sons of light" (4QDa 1:1; 1QS 3-4). ${ }^{41}$ The $S$ tradition actually includes very little material that does not have a parallel of some sort in the $\mathrm{D}$ tradition. The most striking absences in $\mathrm{D}$ are the extensive discourse on the two spirits (1QS 3-4), the metaphors of the temple (1QS 5; 8), and the hymn at the end (1QS 9-10). The D tradition, in contrast, includes more material that is not found in the $S$ tradition. However, it is the kind of material that seems to be presumed by the $S$ tradition in many ways; most notably, the $S$ members could not do without halakah, and probably also not without some understanding of the movement's beginnings, which are found in $\mathrm{D}$.

39 A parallel to the following section is found in $4 \mathrm{QD}^{\mathrm{a}} 8 \mathrm{i}$, but the passage on the oath has not been preserved there.

${ }^{40}$ Column numbers follow Philip S. Alexander and Geza Vermes, DJD 26.

${ }^{41}$ The editors of 4QS manuscripts in DJD mention parallels in the confession of sins (1QS 1:23-2:1 and CD 20:28-30), in the theology about the remnant (1QS 4:14 and CD 2:6-7), and numerous parallels in the penal code material, but admit that the list is only partial, Alexander and Vermes, DJD 26:3. 
This is not to say that the direction of dependence and borrowing always goes from $\mathrm{D}$ to $\mathrm{S}$; most probably it does not, and some of the above parallels can be the work of redactors who wanted to make the documents look more similar. ${ }^{42}$ However, shared elements between D and $S$ and within D and $S$ are so many and show such an important amount of independence that we ought to refrain from dealing with them merely as the work of harmonizing scribes without any counterpart in social reality.

What one makes of these shared traditions is of course the crucial question. It would be too simplistic to claim that the persisting core or the essence of the movement is found in the shared material of D and S. It might not be; some aspects that are represented in one document only might testify to continuing practices in the movement (most likely, halakic practices), and differences between the documents can testify to real differences/changes in the movement (at the least, in the terminology used). But the answers given often fail to appreciate the full significance of the shared material. In the following, one area is investigated that potentially affected the $\mathrm{D}$ and $\mathrm{S}$ members' perceptions, categorization of themselves and identification over time. What the movement was considered to be is reflected in the admission to the group.

\section{Idem Identity upon Admission?}

The procedure of taking an oath is shared by $\mathrm{D}$ and $\mathrm{S}$ traditions $(\mathrm{CD}$ 15:5b-10a; 1QS 5:7c-11a // 4QS $\left.{ }^{\mathrm{b}} 9: 6 \mathrm{~b}-8 \mathrm{~b} ; 4 \mathrm{QS}^{\mathrm{d}} 1: 5 \mathrm{~b}-7 \mathrm{a}\right),{ }^{43}$ and these

${ }^{42}$ The language of light and darkness is otherwise absent from $\mathrm{D}$ traditions and could have been added to align it with the $S$ tradition. I did not include any organizational terminology in the list above; e.g., rabbim terminology is problematic from this perspective: it is found both in $S$ and $D$, but not systematically in either. Hempel, The Laws, 83, argues that it is the work of the $S$ redactors in D.

43 The $4 \mathrm{QS}^{\mathrm{b}, \mathrm{d}}$ manuscripts contain a shorter version of the oath-taking. Most notably, they do not contain the reference to "Sons of Zadok" and "the multitude of the people of their covenant" as receivers of revelation but "the council of the people of the community." Our interest is in the self-categories of members taking the oath, and these differences would not seem to play a great role, unless it can be shown that the authority structure was very different between these traditions, which does not seem likely; cf. Sarianna Metso, "Qumran Community Structure and Terminology as Theological Statement," RevQ 20/79 (2002): 429-44. 
formulations reveal something of what was believed to distinguish members from non-members: they turned to the Law of Moses with all their heart and soul and submitted to what is revealed of the Law. ${ }^{44}$ The oath captured both ideological and practical aspects of the shared social identity: it was about turning back to the ancient, divine Law but in a necessary and practical usage of it within the movement.

According to $\mathrm{D}$, not all were qualified to take the oath, however. The mébaqqèr examined the initiate before teaching the laws (CD 15:10 ff.). S does not refer to an examination in connection to oath-taking but does elsewhere (see below). Instead, the $S$ tradition has separation from the "people of injustice" as a requirement for membership, which is again absent in this block of the $\mathrm{D}$ tradition. The need for separation, however, is found elsewhere in $\mathrm{D}$, for CD 6:11b-7:9a includes a summary of community duties, often assigned to an early layer within the document. ${ }^{45}$

Who are the "people of injustice" according to $S$ ? The sudden change in number from plural to singular is confusing in 1QS 5:13b-15b: "He shall not enter the water to touch the purity of the people of holiness...." Hempel is inclined to reject the suggestion that it would speak of members' insincere conversion. ${ }^{46}$ Instead, she thinks that "we are still dealing with the rival group, the people of injustice, who are so close to the community, or at least some of its members, or have been close in the past, that what is said about them can read like a description of insincere members." This is, in my view, correct, but another question is whether the people of injustice were a rival group ("a clearly recognizable social entity") ${ }^{47}$ or outsiders in general from whom the members needed to distinguish themselves. The

${ }^{44}$ See further Jutta Jokiranta, "Social Identity in the Qumran Movement: The Case of the Penal Code," in Explaining Christian Origins and Early Judaism: Contributions from Cognitive and Social Science (ed. Petri Luomanen, Ilkka Pyysiäinen, and Risto Uro; Biblical Interpretation Series 89; Leiden: Brill, 2007), 277-98. The term nigleh probably refers to scriptures available to all groups (see Lawrence H. Schiffman, Reclaiming the Dead Sea Scrolls: The History of Judaism, the Background of Christianity, the Lost Library of Qumran [Philadelphia: The Jewish Publication Society, 1994: 186-88) but, at the same time, it implies the idea of having knowledge of its exact meaning (parush, CD 6:14), requiring careful study of the scriptures and search for their correct meaning.

45 Hempel, Damascus Texts, 44-49.

46 Charlotte Hempel, "The Community and Its Rivals According to the Community Rule from Caves 1 and 4," RevQ 21/81 (2003): 47-81 (53).

47 Hempel, "Community and Its Rivals," 81. 
people of injustice do not necessarily have a social identity of their own. Part of the social categorization is to accentuate the differences between out- and in-groups, and to accentuate the similarities within the out-group. According to the shared social identity, in-group members were committed to the Law and its revelation, and outsiders were not. ${ }^{48}$ But the members learned these things only gradually as they were taught the rules, and may not yet have grasped in full the differences to some of the outsiders. It was the duty of the maśkîl to "teach them to separate from every man who fails to keep himself from perversity" (1QS 9:20b-21a).

The more elaborate and possibly later admission procedures $(1 \mathrm{QS}$ 5:20b-25a; 6:13b-23; ${ }^{49}$ 1QS 9:12-21; CD 12:11-13) ${ }^{50}$ provide information about the shared social identity but in a different way. In these procedures, examination and the hierarchical structure of the group are emphasized: the candidate is tested about his/her understanding and deeds ${ }^{51}$ and is ascribed his/her position by the superiors accordingly. ${ }^{52}$ If

48 Contacts with the outsiders were then strictly regulated, concerning work, property, knowledge, food and business dealings (1QS 5:13b-17). This was the consequence of adopting the social category.

49 Charlotte Hempel, "Community Structures in the Dead Sea Scrolls: Admission, Organization, Disciplinary Procedures," in The Dead Sea Scrolls after Fifty Years: A Comprehensive Assessment. Vol. 2 (ed. Peter W. Flint and James C. VanderKam; Leiden: Brill, 1999), 67-92 (70), compares the section in $S$ to the oath-taking in CD, and states: "The procedure laid down in 1QS 6:13b-23 reflects a degree of institutionalization."

${ }^{50} 1 \mathrm{QS}$ 1:7b-11a also speaks about bringing in the volunteers but it is not clear if these are rules for the maśkîl (the title has not been preserved although is reconstructed in $4 \mathrm{QpapS}^{\mathrm{c}} 1: 1$ ) or more generally describing the membership ideals.

${ }^{5} \mathrm{CD}$ 12:11-13 includes also skills, power and property that the $\breve{m e b a q q e r}$ investigates. 1QS 1:11b-13 talks about bringing in knowledge, skills and property. Also CD 15:11 mentions testing but does not specify this. Concerning property, both $\mathrm{D}$ and $\mathrm{S}$ members subjected its use to the movement's decisions and, therefore, the difference between handing over two days' wages per month (D) or perhaps all one's property $(S)$ tells only part of the story.

${ }_{52}$ However, the superiors vary from priests + non-priestly members (1QS 5), $p \bar{a} q \hat{\imath} d+\mathrm{rabbim} / \mathrm{priests}+$ non-priests (1QS 6), maśkîl (1QS 9), to $\breve{m} e b a q q e \bar{r}$ (CD 12). More important than the title of the individual(s) doing the examination is the variation between what seem to be one-step procedures and the three-step one in $1 Q S$ 6. If there was a development towards a more lengthy procedure (so Hempel, "Community Structures," 67-93) or if such a procedure was only practiced in some groups but not others, there would be a potential difference in 
these passages reflect the actual procedures, a person who goes through such an admission understands him/herself to be qualified: outsiders are those who did not qualify or do not even seek to be qualified. Furthermore, such a person knows his/her place in the hierarchical order of the group, even in the cosmic order, if the discourse on two spirits is to be believed. ${ }^{53}$ The person submits to superiors but can also have subordinates, at least in the course of time. The shared social identity is not only about what distinguishes oneself from outsiders, but how, once the candidate is an insider, that difference translates to one's "true self" at a given moment and to relations to other insiders.

A collective admission procedure is depicted in 1QSa 1:2-5: "When they come, they shall assemble all those who come, including children and women, and they shall read into their ea[rs] all the regulations of the covenant, and shall instruct them in all its precepts, so that they do not stray in their [errors]." This is followed by rules for various age groups. In this admission, the emphasis is on instruction and education. The person who joins the group is part of a structured teaching and legal system, meant to keep him/her from erring, or to return him/her to the right track after erring. Outsiders are without such a system of guidance.

Lastly, we can take a look at the collective renewal of the covenant (1QS 1:16-2:12: // 4QS $2: 1-13$; 3:1-4; CD 14:3-6a; 4QDa 11 17-18a // $4 \mathrm{QD}^{\mathrm{e}} 7$ ii $11-12 \mathrm{a}$ ), which presumably was an annual procedure. Liturgies are effective means of promoting a shared understanding of group membership..$^{54}$ According to $S$, this liturgy included praise of God's deeds, confession of sins, blessings on the lot of God and curses on the lot of Belial. The dividing line between the insiders and outsiders went, according to this line of thought, not between those who sin and those who do not, but rather between those who confess their sins and those who do not or who

social identities; at least, the sense of qualification of the candidate would be much stronger with those participating in the lengthy procedure.

53 In light of the discourse on the two spirits, the ranking was fundamentally God's work: he created every person with a share of spirit of light and spirit of darkness (1QS 4:26; 9:12-14). Rather than a crucial difference in comparison to D (cf. Davies, "The Judaism(s) of the Damascus Document," 38), this discourse seems to me to offer the members yet a further, most abstract identity category, according to which they were expected to view the world and the universe.

${ }^{4}$ See, e.g., Russell C. D. Arnold, The Social Role of Liturgy in the Religion of the Qumran Community (STDJ 60; Leiden: Brill, 2006), 59-80. 
accept a "hardened heart" once in the covenant. ${ }^{55}$ The hierarchical order is again stressed.

Does a coherent shared social identity emerge from these passages? In my view, yes, to a certain extent: a member adopted a social identity according to which the voluntary act of joining was necessary in order to align oneself with the covenantal laws. The emphases vary, partly reflecting the further implications of this identity when the member proceeded to cultivate a new identity. Examination and qualification played a role upon admission. ${ }^{56}$ The contents and manner of the testing probably varied from one period to another, if not between the sections of the movement. It has been suggested that a physiognomic investigation of a person's spirit had a part in the decision-making of admitting or excluding a person. ${ }^{57}$ The physiognomic and astrological knowledge was, however, restricted to a small number of intellectuals, possibly the community leaders, ${ }^{58}$ so it is not very likely that the outward appearance of the members as such would have been seen as distinguishing them from outsiders. In general, the standards of membership were apparently different for those joining and for those already accepted and instructed in the community; more was demanded from senior members (1QS 7:22-25) and they had more power. A member who experienced the cursing of the outsiders for the first time came to realize what his/her new membership meant.

55 The D fragments include a similar idea about one who rejects these laws and is being cursed but they do not include the confession of sins (4QD $115 \mathrm{~b}-$ $16 / / 4 Q^{\mathrm{e}} 7$ i 19b-21).

56 In light of 1QS 5:7-13, it is possible that, at some stage or in some groups, there was no examination at all. However, see below.

${ }^{57}$ Most recently, this is cautiously suggested by Mladen Popović, Reading the Human Body: Physiognomics and Astrology in the Dead Sea Scrolls and HellenisticEarly Roman Period Judaism (STDJ 67; Leiden: Brill, 2007), esp. 230-39. Horoscope texts (4Q186; 4Q561) testify to the belief in the close connection between one's outward appearance and one's characteristics and fate determined by the date of birth and the position of stars. According to Popović, investigating the "spirit" does not refer to evaluating the human spirit but the person's zodiacal sign and the related zodiacal spirit which could be potentially harmful (172-208). The movement possibly wanted to exclude persons that could more likely pose a threat to the whole group. Popović also suggest that physiognomic inquiry could have been used as diagnostic tool "to determine the kind of treatment and cure for the community members attacked by zodiacal spirits of a less harmful nature" (239).

58 Popović, Reading the Human Body, 215-32. 4QZodiacal Physiognomy was also written in a cryptic manner. 
A further question is which role the admission passages are given in the overall understanding of the identity construction in the movement. The debate on the small groups of 1 QS $6: 1 b-7 a$ is relevant in this regard. The "groups of ten" form a part of the shared traditions of D and S, but were such groups a continuing reality in $S,{ }^{59}$ or rather historical memories from the past, ${ }^{60}$ or rules for restricted, specific purposes? ${ }^{31}$ If $1 \mathrm{QS} 6$ is considered to reflect the historical primitive setting where "likeminded Jews" gathered together to eat, pray and exchange counsel, as Hempel thinks, ${ }^{62}$ there would be no identity based on the specific act of changing one's life and on qualification and examination-or would there? The very idea of setting up a "voluntary association" includes selection, breeding and cultivation of the members. Either these individuals already had a very elite understanding of themselves and of how things were run, or the oath-taking or some kind of admission was presumed in this passage. I think the

59 John J. Collins ("The Yahad and 'the Qumran Community'," in Biblical Traditions in Transmission: Essays in Honour of Michael A. Knibb [ed. Charlotte Hempel and Judith M. Lieu; JSJSup 111; Leiden: Brill, 2006], 81-96 (86)) argues that 1QS 6:1b-7a refers to small groups (yahad being an umbrella term for them) whereas the following section, 1QS 6:8b-13a, speaks of "an assembly rather than a community" and could refer to something like "the assembly of all the camps" in D (CD 14: 3). See also Torleif Elgvin, "The Yahad Is More than Qumran," in Enoch and Qumran Origins: New Light on a Forgotten Connection (ed. Gabriele Boccaccini; Grand Rapids, Mich.: Eerdmans, 2005), 273-79.

${ }^{60}$ Hempel, "Interpretative Authority," 61-68, argues that the section 1QS 6:1c-8a is composed of three literary layers, which were brought together because of common themes and catchwords. In her view, the earliest layer in $1 Q S 6: 1 c-3 a$ "gives the impression of going back to the earliest and simplest beginnings of communal life, if it can be called that, where small numbers of individuals congregated to eat, pray, and take counsel together." Also Charlotte Hempel, "Emerging Communal Life and Ideology in the S Tradition," in García Martínez and Popović, eds., 43-61 (45) writes: "I see no reason to presuppose that the highly developed communal structure described elsewhere in $S$ co-existed with the primitive scenario outlined here."

${ }^{61}$ Metso, The Textual Development, 135. She ("Whom Does the Term Yahad Identify?" in García Martínez and Popović, eds., 74-84 [75-76]) considers the possibility that 1 QS 6:1-8 was preserved in $S$ for the occasions when members of the yahad travelled and lodged in small Essene settlements in towns and villages. However, Metso acknowledges problems with this interpretation, and eventually considers this passage as a "time-honored set of directives," deriving from earlier settings (77).

${ }^{62}$ Hempel, "Emerging Communal Life," 45. 
latter is more likely: the passage is otherwise concerned with similar matters as many other rules for assemblies: hierarchical order, ratio of priests, giving and taking counsel. If some qualification played a role, the setting is perhaps not that primitive; they had a clear program. Or alternatively, we could think that the essential activities of the $S$ members were considered to be this simple. $S$ can have more to do with assemblies than with communities. ${ }^{63}$ Rules convey to us a lot of information about these groups, but most of all, they convey the movement as it wishes itself to be preserved in the eyes of new members and in the teaching of the senior members. ${ }^{64}$ Both $\mathrm{D}$ and $\mathrm{S}$ members relied on the counsel of their superior members, such as the maśkill and the mĕbaqqèr, in their everyday life, and perhaps saw that counsel being given primarily in small group assemblies. ${ }^{65}$

\section{Conclusion}

It is a matter of what the movement is considered to be as to how much variation is allowed in it for it to be considered the same over time. This analysis concerning the hypothetical members of $\mathrm{D}$ and $\mathrm{S}$ was very focused, yet this thought-experiment runs the risk of harmonizing the sources. The

63 This is in contrast to the argument by Sarianna Metso, "Whom Does the Term Yahad Identify?" in Biblical Traditions in Transmission: Essays in Honour of Michael A. Knibb (ed. Charlotte Hempel and Judith M. Lieu; JSJSup 111; Leiden: Brill, 2006), 213-35 (219), that 1QS 6:8b-13a is a later interpolation, and "the organizational terminology in sections regulating community life in $1 \mathrm{QS}$ VVII-if VI, 1c-8a is removed-seems to be envisioning a relatively consistent community structure and hierarchy and a sizeable community." The size of the movement the candidate joined is also not irrelevant in terms of social identity.

${ }^{64}$ The sĕrākîm may not have so much to do with conflict with out-groups, or distinguishing from the out-groups, but with the question of how to harness the personal identity into the service of the social identity, how to safeguard the purpose of the community, and how to deal with the contesting identities within the groups (e.g., tasks of the maśkîl).

${ }^{65}$ On a sociological level, Cecilia Wassen and myself have attempted to show that despite the differences between $\mathrm{D}$ and $\mathrm{S}$, a common sectarian stance can be perceived behind both documents. See Cecilia Wassen and Jutta Jokiranta, "Groups in Tension: Sectarianism in the Damascus Document and the Community Rule," in Sectarianism in Early Judaism: Sociological Advances (ed. David J. Chalcraft; London: Equinox, 2007), 205-45. 
analysis already suggests, however, that in their perception of admission, group activities and language, foundations for common in-group identity and continuity of that identity are perhaps much stronger than previously thought. The movement was concerned with a total commitment to the Torah within the framework of the counsel of the members.

What the movement was thought to be can better be conceived of on the basis of its activities rather than on its social set-up. The idem identity was not defined in relation to distinct forms of communities (even if these existed). The sameness of such a movement could, for example, be defined by principles visible in the annual assembly: if boundaries surrounding whom to accept and whom to exclude, or the authoritative principles would be dramatically changed, the movement could be seen as another movement. Titles, terminology, number of participants, process of admission or rules of behavior for assemblies were more likely to be considered as subject to changes - the movement could be perceived as the same movement. Of course, changes in the environment and differences between groups might also give rise to schisms or segregation. Theoretically, any difference between $\mathrm{D}$ and $\mathrm{S}$ could have been adopted as a crucial identity marker and used in the construction of a new identity. However, the admission procedure did not show evidence of this. Any study of the relationship between $\mathrm{D}$ and $\mathrm{S}$ should examine the flexible and hierarchical nature of social identities and take these perspectives into account in the movement's reconstruction.

The movement naturally had a flow of people in and out. Different community terminology and emphases can, to a large extent, be explained as attempts to find the most suitable tools for promoting group cohesion and necessary theological views for a particular setting. Group cohesion is not only challenged from the outside. The social identity approach shows how the group needs to defend its social identity over time: contesting claims naturally arise within a group. Achieving an agreement on the fundamental contents of the in-group identity is an ongoing process. Scholarship benefits from non-Qumran centered thinking, even if one supports the existence of a "community at Qumran." A movement that remains, at least for the greater part, among outsiders, and which functions both on a small scale as well as has larger gatherings, is able to include a rich array of variation in it and also preserve its sameness. 